\title{
UNUSUAL LOCALIZATION AND PRESENTATION OF NON- VISCERAL HYDATID CYSTS: REVIEW ARTICLE
}

By

\author{
REFAAT M. KHALIFA AND RAGAA A. OTHMAN \\ Department of Parasitology, Faculty of Medicine, Assiut University, Assiut, Egypt \\ Corresspondence address: rkhalifa_eg@yahoo.com
}

\begin{abstract}
Echinococcosis is a major parasitic zoonosis of public health importance worldwide. This is particularly true in sheep-raising countries including Egypt. Therefore, it is very important to identify the significant risk factors of the diseases by reviewing studies done in the region in the past decade to help policy makers design appropriate control strategies.
\end{abstract}

Key words: Hydatidosis, Unusual sites, subcutaneous, muscloskeletal

\section{Introduction}

Echinococcal disease in humans is a parasitic tapeworm infection caused by a larval stageof Echinococcus species (E. granulosus, E.multilocularis, E. oligarthus, E. vogeli). The infection can be asymptomatic or severe, causing extensive organ damage and even the death of the patient (Delis et al, 2007). Hydatid cyst (HC) has a worldwide distribution and has been recognized since ancient times. Human hydatidosis is a parasitic infection of the liver and other organs caused by the flatworm Echinococcus granulosus; a tapeworm that has dog, foxes or coyotes as the definitive host and sheep, swine, cattle, and zebra as the intermediate host. Man is an accidental intermediate host and infection of humans represents a terminal event (dead end) for the parasite. Once within man or other intermediate host the ingested eggs hatch in the duodenum to release the oncospheres that penetrate the mucosa of small intestine and enter the portal circulation. Liver acts as the first effective filter for most of the larvae and therefore being the most common site of involvement (65-75\%). If the larvae pass through the first filter, they reach the lungs which are the second most frequently involved site (10$25 \%$ ). If the larvae are not trapped in either liver or lungs, or if they by-pass the liver by traveling via lymphatics, it may lodge itself in any part of the body including the perito- neal cavity (8-18\%), spleen (2-3\%), kidneys $(1-4 \%)$, uterus and adnexia $(0.5-1 \%)$, retroperitoneum $(0.5-1 \%)$, pancreas $(0.5-0.8 \%)$ (Palaivelu, 2007), subcutaneous (1-2\%) (Zulfikaroglu et al, 2005), mediastinum (0.1-0.5\%) (Kabiri et al, 2007), gall bladder $(\leq 1 \%)$ (Raza et al,2003), brain $(2 \%)$ (Greenberg,2001), seminal vesicle (Safioleas et al, 2006), spinal (Drimousis et al,2006) and others $(0.1-3 \%)$. The exact percentage of site involvement varies and the exact incidence of unusual locations is difficult to ascertain as they are only reported as case reports(Zippi et al,2007).A high index of suspicion, radiological investigations as well as histopathological examination is necessary in establishing the diagnosis of hydatid disease (HD) at unusual sites of the body(Wani et al,2013).

Hydatid cysts with unusual localization may cause serious problems in their differential diagnosis (Ozturk et al, 2001). The present article aims to throw light and comment on these locations and presentations of subcutaneous and muscloskletal tissues.

1- Subcutaneous (SC) hydatidosis: Soft tissuesis one of the unusual localizations of HC (Memis et al, 1999). A high level of awareness concerning their occurrence is important especially in regions where HD is endemic (Dudkiewicz et al, 1999). However, the ease and frequency with which people travel makes it important for physicians 
in most parts of the world to be familiar with these cysts (Safioleas et al, 2008).A preoperative diagnosis of subcutaneous HCs is a must to avoid post-operative complications (rupture, dissemination and anaphylaxis), surgeons in particular should be aware of the unusual locations of this rare disease (Satywati et al, 2013). SC hydatidosis may be primary or secondary to involvement of other visceral organ. Herein are some examples of these presentations:

Chevalier et al. (1994) presented a case of 40 year old man (originally from Portugal and living in France for 20 yearscomplaining of a slightly tender mass of the posterior aspect of the left thigh. Sonography revealed a $15 \mathrm{~cm}$ hypoechoic mass in the subcutaneous tissue adjacent to the muscles. Surrounding muscles were compressed but were otherwise normal. Immunological tests for echinococcosis were negative.Postoperative histology showed no protosclices (sterile cyst). However, PCR on the DNA extracted from the cyst fluid was positive for HC.

Memis et al. (1999) reported a 41 year old female who presented with a slowly enlarging mass in the right thigh. MRI showed $8 \times 6 \times 4.5 \mathrm{~cm}$ cystic mass in the cranial part of the popliteal fat fossa with no muscular invasion. Fine needle aspiration cytology (FNAC) revealed the clear colorless fluid diagnostic of HCs and histological examination of the extracted cyst confirmed the diagnosis. They concluded that MRI provides valuable information in the diagnosis of $\mathrm{HC}$ by showing multiseptated or multicystic mass surrounded by a rim as well as characterizing and depicting the extent of the lesion.

Eroglu et al. (1999) reported a 66 year old Turkish woman farmer complaining of a painless, slowly growing swelling in the nape of the neck $(8 \times 7 \mathrm{~cm})$ tender mass without any hepatic or pulmonary involvement. IHA for hydatidosis was negative but FNAC revealed HC structure.

Dudkiewicz et al. (1999) reported HC presenting as a soft tissue thigh mass in a young boy and Ozturk et al. (2001) described a case of a primary SC mass arising in the molar region. Histological findings were consistent with soft tissue HC.

Cannon et al. (2001) reported two cases of soft tissue HC. They recommended the current treatment of choice by wide resection combined with perioperative medical therapy. Orhan et al. (2003) recorded unusual case of primary SC hydatidosis in proximity of vastus lateralis muscle in a 43 year old female with pain at the proximal thigh region. A $4 \times 5 \mathrm{~cm}$ mass was palpated over the greater trochanter. IHA for hydatidosis was negative but its diagnosis as echinococcosis was confirmed preoperatively after CT visualization of the cyst wall.Pampori et al. (2003) detected a 15 year old female who presented with a slowly growing non-tender swelling in theneck of 8 month duration. It has a smooth surface and firm consistency and did not move with deglutition or protrusion of the tongue. FNAC and histology confirmed $\mathrm{HC}$.

Katilmis et al. (2007) recorded a 33 year old woman who presented with one year history of painful gradually growing moderately hard $4 \times 4 \mathrm{~cm}$ mass located in the right juglodigastric region of the neck. The mass was thought to be a branchial cleft cyst. On pathologic examination, it was found to have germinative layer and daughter cysts consistent with HC and Yilmaz et al. (2007) presented a case of an isolated HC localized in the subclavicular region without any pulmonary or hepatic involvement.

Dirican et al. (2008) described two cases of SC hydatid cysts occurring in the palm and thigh. Case I was 64 year old male farmer with a swelling on right medial thigh of one year duration. CT revealed a lesion resembling $\mathrm{HC}$ and germinative membrane was encountered during surgical excision. Histologically, the structure was consistent with HC. Case II was 67 year old male farmer with swelling on the left palm between the index and middle finger. Its preliminary diagnosis was a lipoma. However, 
a HC was diagnosed during surgical excision and after histopathological examination. Safioleas et al. (2008) recorded a 73 year old malecomplaining of 8 year history of slowly growing mass in the left gluteal area measuring $6 \times 5 \mathrm{~cm}$. It was hard on palpation but without pain and evident muscle fixation. High esinophilia raise the suspicion for $\mathrm{HC}$ which was confirmed histopathologically. As there was no other visceral invasion, they were astonished why the hatched echinococcal embryos bypass the liver and lung and suggested immediate inoculation with eggs via dog bite. Although this theory has not been generally accepted, they have encountered a patient with $\mathrm{HC}$ of the neck who had been bitten by a dog in that site.

Ahmad et al. (2010) reported a case of 46 year old man with a slightly tender gradually growing swelling in the posterior cervical region of 5 months duration. Ultrasound report suspected complicated HC. However, his IgG serology for HD was negative and FNAC revealed fibrofatty stromal fragments with many scattered scolices, hooklets and calcareous corpuscles.

Bansal et al. (2011) reported an exceptional occurrence of primary $\mathrm{HC}$ in the soft tissues of the face. A 45 year old manworking in navy presented with painless gradually growing $6.2 \times 3.5 \mathrm{~cm}$ swelling in the right temporal region of 2 years duration It was not adherent to the underlying bone. Postoperatively, there were multiple clear fluid filled unilocularcysts measuring 1.5 to 3.0 $\mathrm{cm}$ in diameter. Microscopically, a lamellated ectocyst with germinal endocyst consistent of HC was demonstrated. They concluded that that case report pointed out (1) to bear in mind the differential diagnosis of HC while dealing with the cysts of the head and neck (2)imaging techniques, though sensitive, sometimes cannot pin point the exact etiology of the cystic lesions (3) FNAC of a cyst located on the face may cause anaphylactic reaction and one should be ready for the consequent emergency (4) during surgical removal, great care must be taken to avoid spilling of the cyst contents. Iynen et al. (2011) reported a primary $\mathrm{HC}$ as one unusual cause of a mass in the supraclavicular region of the neck. A 21 year old Turkishwoman presented with a history of painless lump growing in the left lateral side of the neck. Physically, there was a uniform mobile smoothly outlined mass with a diameter of $5 \times 4 \mathrm{~cm}$ on the supraclavicular region of the left lateral neck. MRI showed the characteristic features for HC and IHA for hydatidosis was positive which was confirmed histologically postoperatively. Another primary cervical HC was recorded by Sultana et al. (2012). A 20 year old Pakistani female who presented with one year history of a slowly growing occipitocervical mass that was painless and without fever. Clinical examination revealed cystic fluctuant $7 \times 7 \times 4$ cm swelling.

Chakrabarti and Goswami (2012) reported a primary $\mathrm{HC}$ of the neck in a 58 year old Indian male who has a $45 \times 30 \mathrm{~mm}$ swelling in the right posterior triangle of the neck of one month duration, the size of which then was that of a pea.It was gradually increasing but was painless. Clinically, there was no attachment to deeper tissues and it was diagnosed as cold abscess. However, FNAC yielded $5 \mathrm{ml}$ of mildly dirty fluid with some white granularity. Microscopically, hydatid scolices and hooklets with few fragments of lamellar membrane in a dirty background of pus cells and cell debris were seen; leading to a diagnosis of infected HC. They concluded that their unique presentation proved that although FNAC is generally discouraged due to risk of anaphylaxis, yet it accidently clinched the correct diagnosis in their case. Jabroui et al. (2012) recorded a soft tissue mass in the supraclavicular region of the neck. Their case was of a 53 year old woman who presented with three month history of painful mass growing on the left lateral side of the neck. Physically, somewhat hard painful and fluctuant mass of $10 \times 7 \mathrm{~cm}$ was palpable on the supraclavicular region of the lateral neck. The overlying skin was 
inflammatory without regional lymphadenopathy. Erythrocyte sedimentation rate was $40 \mathrm{~mm} /$ hour. CT scan demonstrated a binocular mass on the left supraclavicular region with cystic aspect. Thus, the patient was diagnosed as having pyogenic abscess or tuberculosis. The mass was excised and the diagnosis was confirmed perioperatively after vesiculation of cyst wall and daughter cysts which was confirmed histologically.

Burgazliet al. (2013) reported unusual localization of a primary $\mathrm{HC}$ as a SC mass of the paraumbilical region in a 63 year old Turkish male complaining of abdominal distension and pain and having abdominal mass of one year duration. The mass was $4 \times 5 \mathrm{~cm}$ in the left quadrant paraumbilical region. Postoperative histology confirmed HC. They concluded that when a SC mass is detected in a patient regarding the region where he lives and endemicity, HC should be considered.Satyawati et al. (2013) recorded a secondary $\mathrm{HC}$ presenting as a mass in the supraclavicular region in a 28 year old Indian female complaining of a progressive painless swelling in the right supraclavicular region for 6 years. Physically, it was $6 \times 3 \mathrm{~cm}$, soft, non-tender, transiluminant, non-compressible and non-expansile lesion in right supraclavicular fossa which divides subscapularis and solenus antecus as anterior, posterior and medial limitations with preserved fat planes. FNAC was consistent with $\mathrm{HC}$ which was further confirmed by postoperative histology. Mujtaba et al. (2013) detected a primary $\mathrm{HC}$ of the neck in a 7 year old Pakistani boy complaining of a slowly growing mass in the left side of the neck. Physically, he had a $4.5 \times 3 \mathrm{~cm}$ painless immobile cystic mass in the anterior triangle of the neck. Ultrasound showed the cystic mass and serological tests were negative for hydatidosis. Postoperatively, the patient had grossly a single egg-shaped grayish white encapsulated cystic mass. Cut surface was filled with clear fluid. Microscopically, hydatidscolices were seen.
2-Skeletal muscle (SM) hydatidosis: Primary (SM) infestation with $\mathrm{HC}$ is rare and account to $1-4 \%$ of reported hydatid cases (Palmerio et al, 1993). This low prevalence may be due to physical barriers to the hematogenous dissemination of cysts created by hepatic sinusoids and pulmonary capillaries. However, higher lactic acid concentration in SMs and mechanical factors such as contractile activity may make encystations less likely (Polat et al, 2003). Herein are some examples of these presentations: HCs were reported by Abdel-Khaliq and Othman (1986) in pectoralis major muscle, Vietri et al. (1988) in Sartorius muscle.Duncan and Tooke (1990) recorded an extremely unusual case of an intramuscular $\mathrm{HC}$ in the biceps brachii of a 41 year old American man. Clinically, it resembled a soft tumor but the diagnosis of $\mathrm{HC}$ was made by incisional biopsy. They concluded that the report served as alert to this rare but potentially fatal condition as preoperative diagnosis is imperative to avoid its inadvertent rupture which releases viable solaces into the systemic circulation and may participate an anaphylactic reaction.Manes and Santucci (1990) reported a secondary case of muscular hydatidosis which followed hepatic and pulmonary localizations. They concluded that muscular localization seemed to be related to the regional circulation. Lamine et al. (1993) reported seven cases of primary hydatidosis in young (average 29 years old) women in rural areas; 5 cases in the thigh and 2 in the adductors compartment and Yorukoglu et al. (1993) reported a primary HC originating in the adductor muscle group leading to obstruction of femoral artery and vein. Casero et al. (1996) reported an unusual case of HD localized in the gluteus muscle in a 49 year old-woman who lived in a rural area of Argentina. She has had an abscessed tumor like mass located in the upper zone of the right gluteus muscle. Shehad received intramuscular medication in the same muscle severaldays before admission. It was thus realized that there was a relationship between the 
needle puncture and development of the abscess. The latter was drained, yielding 100 $\mathrm{ml}$ of colorless transparent fluid containing scoleces and hooklets. They concluded that such disease may be overlooked if clinicians fail to consider the possibility of parasitic involvement at unusual sites. El-Moussaoui et al. (1997) reported HC in the psoas muscle in a 28 year old woman. She presented with left iliac fossa mass. Ultrasonography (US) and Ct contributed to the preoperative diagnosis, despite negative serology.

Bayram and Sirikci (2000) presented the MR imaging of a primary $\mathrm{HC}$ located in an intramuscular area of the forearm.Daali and Hssaida (2000) posed a report of 15 cases of muscle hydatidosis during 8 year period. Patients were predominantly young adults, $\mathrm{M} / \mathrm{F}$ ratio $2 / 1$. Clinical signs included pain, particularly for deep localizations and tumor-like masses for superficial localizations. A second hepatic localization was found in 5 cases and a splenic localization in one case. Sonography and CT provided the diagnosis of all cases. Localizations included the diaphragm ( 7 cases) psoas ( 3 cases) and buttock, biceps, Sartorius, anterior tibialis and intercostal muscles (one case each).

Tatari et al. (2001) detected intramuscular hydatidosis in supraspinatus muscle in a 25 year old Turkish man with 2 months history of a painless enlarging mass in the posterior aspect of the right shoulder without fever, weight loss or trauma. Physical examination revealed a 10x12 cm mass but shoulder's motion was normal and without axillary lymphadenopathy. There was no bone destruction or calcification. The mass resembled a soft tissue tumor but it was proved to be HC by MRI appearance and histopathology. IHA, ELISA and IFA were positive in $1 / 8000,1 / 1024$ and $1 / 64$ respectively. Thursky and Torresi (2001) reported a primary muscle $\mathrm{HC}$ of the thigh in a 63 year old Greek man complaining of a painful swelling in his left thigh which developed over 3 days and was associated with fever, rigors and pruritus. Investigations demon- strated a normal WBC count, high esinophilia and ESR of $80 \mathrm{~mm} /$ hour. A preliminary diagnosis of pyomyositis was made. Formal drainage of the supposed abscess showed multiloculated cavity containing multiple cysts consistent with HD and histologically confirmed HC.

Ozkoc et al. (2003) reported primary HD of the quadriceps muscle in a 48 year old Turkish man who presented with a painless very slowly growing mass in his left vastusmedialis of the quadriceps muscle persistent for approximately 10 years and was $15 \times 19 \mathrm{~cm}$ in size. MRI and postoperative histology were consistent with HC. Atlalay et al. (2003) detected an unusual case of HC in the erector spinae muscle in a 60 year old Turkish male which was diagnosed by US, $\mathrm{CT}$ and MRI to be a HC.

Togrul et al. (2004) reported a solitary HC of the soleus muscle. Turki et al. (2005) reported a patient presenting with a slowly growing mass of the pterygoid muscle which was proved by $\mathrm{CT}$ scan to be a HC. Kazakoset al. (2005) reported primary HD in femoral muscles in the left thigh of 35 year old Greek woman presenting as enlarging soft tissue $14.5 \times 7 \mathrm{~cm}$ tumor. US, CT and MRI revealed a multilocular intramuscular cyst in the anterior quadrant of the left thigh. Excised cyst was grossly and microscopically consistent with muscular HC. Mseddi et al. (2005) recorded eleven cases of HCs in muscles in Tunisia over a 17 year period. The proximal muscles of the limbs were involved predominantly. US confirmed the diagnosis of all cases. Marwah et al. (2005) presented a case of infected primary intramuscular echinococcosis of the quadriceps muscle in an 11 year old Indian girl who presented with progressively increasing one year old swelling in the right thigh following doubtful history of trauma. Ten months prior, there was a history of needle aspiration of thin fluid from the swelling and it subsided thereafter. The swelling recurred after a few months and became painful. Physically, there was a diffuse intramuscular swelling 
occupying the anterior region of the right thigh measuring $11 \times 7 \mathrm{~cm}$ with signs of local inflammation. The clinical possibilities of soft tissue sarcoma and infected hematoma of the muscle were made, but US was suggestive of $\mathrm{HC}$ and positive serology confirmed it as infected $\mathrm{HC}$.

Rokni et al. (2007) reported a case of primary adductor muscle hydatidosis in a 50 year old Iranian housewife who presented with 6 month history of a slowly growing mass in the anteromedial aspect of her left thigh. Physically, the mass was $6 \times 5 \mathrm{~cm}$ in size, mobile, painless and firm. US and MRI were in agreement with HC. Subsequent serology for hydatidosis was positive and postoperative histology was consistent with HC. Vicidomini et al. (2007) reported an unusual case of primary muscular hydatidosis in proximity of the big adductor muscle in a 34 year old Italian man $(13 \times 8 \mathrm{~cm}$ in size).HD was proved by US and MRI while serological tests were negative. Histopathological examination of the excised cyst was not determined in the diagnosis, but further serological tests for hydatidosis $\operatorname{IgE}, \operatorname{IgG}$ and PCR were positive. Ates and Karakaplan (2007) reported primary HC in the biceps brachii and gluteus muscles behaving as enlarging soft tissue tumors. They concluded that in geographical regions where HD is endemic, HC should be included in the differential diagnosis of a muscular cystic mass to avoid fine needle biopsy and the consequences of spillage of cyst contents. Cankorkmaz et al. (2007) detected an intramuscular HC in the left thigh of a 4 year old girl which was localized between the adductor and iliopsoas muscles.

Sarisoy et al. (2008) reported a 31 year old man who had a growing mass in the posteromedial part of the adductor muscles of his right thigh. US, MRI and serological tests were consistent with HC. Srivastava et al. (2008) presented an unusual case of HC in anterior abdominal wall in a 14 year old Indian male. On physical examination, 10x6 $\mathrm{cm}$ parietal swelling in the right lower ab- dominal wall was encountered. It was nontender and firm on consistency with normal overlying skin. US was in favor of muscle $\mathrm{HC}$ which was confirmed by positive $\mathrm{IgG}$ serology. Basarir et al. (2008) reported 5 Turkish cases of primary muscular hydatidosis mimicking soft tissue tumors. Case I was a 33 year old man with 6x6x5 cm mass in his tibialis anterior muscle. During surgery, the cyst was ruptured and the patient had had a recurrence at the same location 8 months later. Case II was in a 37 year oldman with a $4 \times 6 \times 7 \mathrm{~cm}$ mass in the gluteus maximus muscle. Case III was in a 63 year old woman with a $20 \times 12 \times 15 \mathrm{~cm} \mathrm{HC}$ in the gracilis muscle. Case IV was in 75 year old woman with a $20 \times 5 \times 5 \mathrm{~cm}$ HC in the biceps femoris muscle. Case $\mathrm{V}$ was in a 34 year old woman with a $4 \times 3 \times 2 \mathrm{~cm} \mathrm{HC}$ in the gastrocnemius muscle.

Notarnicola et al. (2009) reported a case of primary intramuscular $\mathrm{HC}$ in a 79 year old woman who presented with a 3 year history of a painful lump in her proximal left thigh. They documented exceptional giant dimensions of the cyst which was not previously reported in a case of striated muscular HD.

Benhaddou et al. (2010) presented an unusual case of $\mathrm{HC}$ located in the trapezius muscle in a 10 year old girl. Bilanovec et al. (2010) reported a lesion of the femoral nerve by a $\mathrm{HC}$ of the right psoas muscle of a 36 year old Serbian male complaining of abdominal pain, weakness of the right thigh and weight loss for one year. US, MRI and CT located right heterogenous solitary lesions in the psoas muscle in close contact with the kidney. Neurological examination showed loss of function of the right femoral nerve. Serology was negative for echinococcosis. There was infiltration of the right femoral nerve and compression of the right ureter. Total cystectomy was carried out with meticulous dissection of the left ureter, gonadal muscles, hypogastric nerve plexus and the right femoral nerve.

Bouraoui et al. (2011) notified an unusual presentation of a forearm $\mathrm{HC}$ in 23 year old 
Tunisian woman who presented with a history of slowly growing mass on her forearm over the past 65 days. On physical examination, the mass was $14 \times 7 \times 6 \mathrm{~cm}$, painful, warm and erythematous. Her fingers were retracted and Volkmann syndrome was suspected. US and MRI were suggestive of a tumor or abscess. Surgery was performed because the cyst was infected and there was a risk of spread of the disease. At surgery, hydatidosis was confirmed as many daughter vesicles were identified and flexor muscle necrosis and fibrosis were noted.

Bharati and Pal (2012) recorded a primary $\mathrm{HC}$ in gastrocnemius muscle in a 52 year old Indian female complaining of a gradually increasing swelling of the right calf region associated with pain for 6 months. Pain was aggravated on walking. Radius of the swelling was $10 \mathrm{~cm}$. US suggested atypical Backer's cyst. After excision, multiple locular cysts were found within the large cystic cavity which was consistent with HC. Alimehmeti et al. (2012) reported saphenous neuropathy due to large $\mathrm{HC}$ within long adductor muscle. Abhishek et al. (2012) reported an abdominal wall $\mathrm{HC}$ in a 60 year old Indian woman with swelling in the right para-umbilical region evolving over a year. Physical examination revealed painless $15 \times 10 \mathrm{~cm}$ cystic swelling with positive cough impulse and dilated overlaying veins. A provisional diagnosis of paraumbilical hernia was made. US showed a cystic lesion in $\mathrm{SC}$ and muscular plane and a preoperative diagnosis of a probable HC was made. Surgical exploration revealed a cystic mass arising from the parietal wall with no adhesions to the omentumor bowel which was confirmed histologically to be a HC.

Gupta et al. (2013) reported an intramuscular $\mathrm{HC}$ of the adductor magnus muscle and called attention to its atypical localization which should be taken into consideration in practice of Surgery Cyst was diagnosed with US and CT pictures. Boyaci et al. (2013) recorded a primary HC of the deltoid muscle in a 48 year old Turkish man who presented with a swelling in the right shoulder of 8 month duration. Physically, there was an immobile soft viscous mass in the anterior of the right shoulder without deficit in motor sensation. MRI denoted 100x56 mm mass containing multiple cystic structures (daughter cysts) of various sizes and IHA test was positive at 1/512 titer. Diagnosis was confirmed histopathologically. Karakas et al. (2013) reported an infected primary $\mathrm{HC}$ in the sartorius muscle in a 30 year old Turkish female which was $5 \mathrm{~cm}$ in size surrounded by erythema and warmth of the skin. US and MRI identified an infected HC.Sezer et al. (2013) reported in 1999 a case of primary recurrent $\mathrm{HC}$ of the tibialis posterior musclein a 55 years old Turkish woman with a soft slightly tender fixed mass measuring $5 \times 5 \mathrm{~cm}$ in her left leg, her IHA test was positive for hydatidosis. She underwent excision of the cyst while receiving chemoprophylaxis with Albendazole $400 \mathrm{mg}$ twice a day for ten days. In 2002 due to recurrence of the disease, the patient was reoperated with repeated chemotherapy for 13 weeks. In 2008, the patient's complaints recurred again. On laboratory examination, more specific serological tests, specific IgG for HD was positive where complete excision with surrounding healthy tissue were removed with no recurrence for 2 years. They did not explain the cause of such very unusual presentation of a primary twice recurrence of $\mathrm{HC}$ in spite of conjunction of surgical and medical treatment.

\section{Comments and Conclusions}

Non-visceral HC presentation seems to lead a successful parasitism in their unusual localizations which is clear from their normal development as in their favorable usual visceral habitations. Most of the presented cases were fertile cysts containing protoscolices, brood capsules and even daughter cysts. Moreover, they were able to attain a big size; not less than $4 \mathrm{~cm}$ but in some cases it reached $15-20 \mathrm{~cm}$ or more. There were no age or gender limitations for their growth as they were reported in 4-7 years old children 
as well as in 75 years old people. HCs with unusual localization may cause serious problems in their differential diagnosis as they may be mistaken for abscesses, benign and malignant tumors. Their identification depends mainly on US, CT, MRI pictures. Most of cases shows negative serological tests even with well-developed cysts but this does not rule out their occurrence. HCs of soft tissues should be put in consideration in cases of any cystic swelling particularly in endemic areas. Surgeons in particular should be aware of these unusual locations to avoid postoperative complications. Revising the available literature, no Egyptian cases of soft tissue HCs were reported.

Finally, more studies are recommended to find out why and how non-visceral HCs are directed to develop in soft tissues unusual locations.

\section{References}

Abdel-Khalique, R, Othman, Y, 1986:Hydatid cyst of pectoralis major muscle echinococcosis. Acta Chir. Scand. 152:469-71

Abhishek, V, Patil, V, Mohan, U, Shivsw-any, B, 2012: Abdominal wall hydatid cyst: case report and review of literature. Case Rep. Surg. 2012, ID583294: 6 pp.

Ahmad S, Jalil, S, Saleem, Y, et al, 2010: Hydatid cyst at unusual sites: reports of two cases in the neck and breast. J. Pak. Med. Assoc. 60, 3:232-4

Alimehmeti, R, Seferi,A, Rroji, A, Alimehmeti, M, 2012: Saphenous neuropathy due to large hydatid cyst within long adductor muscle: case report and literature review. J. Infect. Dev. Ctries. 6, 6:531-5

Atalay F, Orug T, Arda, K, et al, 2003: An unusual case of hydatid disease in the erector spinae muscle. JBR-BTR, 86:329-31

Ates, M, Karakaplan,M, 2007: Hydatid cyst in the biceps and gluteus muscles: Case report. Surg. Infect. 8, 4:475-8

Bansal, C, Nirupma L, Jain, R, et al, 2011: Primary hydatid cyst in the soft tissue of the face: an exceptional occurrence. Indian J. Dermatol. 56, 6:768-70

Basarir, K, Saglik, Y, Yilidz, Y, et al, 2008: Primary muscular hydatidosis mimic-king soft tissue tumor: A report of five cases. J. Orthop. Surg. 16, 3:368-72

Bayram, M, Sirikci, A, 2000: Hydatid cyst located in intermuscular area of the forearm: MR imaging findings. Eur. J. Radiol. 36, 3: 130-2

Benhaaddou, H, Margi, M, Kissra, M, Benhamamouche, M, 2010: Hydatid cyst of the trapizius muscle: an unusual location. Arch. Pediatr. 17, 3:263-5

Bharati, S, Pal, M, 2012: Primary hydatid cyst in gastrocnemius muscle. Nig. J. Surg. 18:1-8

Bilanovic, D, Zdravkovic, D, Randjelovic, T, et al, 2010: Lesion of the femoral nerve caused by a hydatid cyst of right psoas muscle. Srp. Arch. Celok. Lek. 138, 7/8:502-5

Bouranoui, I, Essid, O, Boyghamoura, N, et al, 2011: Forearm hydatid cyst: An unusual presentation. EMHJ, 17, 12:994-5

Boyaci, N, Boyaci,A, Karakas, E, Altay, M, 2013: Primer hydatid cyst of the deltoid muscle. BMJ Case Rep. doi: 10.1136/bcr-2013-200209

Burgazli, K, Ozdemir, C, Ozdemir, B, et al, 2013: Unusual localization of a primary hydatid cyst: a subcutaneous mass in the paraumbilical region. Eur. Rev. Med. Pharmacol. Sci. 17, 13:1766-8

Cankorkmaz, L, Ozturk, H, Koyloglu, G, et al, 2007: Intramuscular hydatid cyst in a 4 year old child: A case report. J. Pediatr. Surg. 42:1946-8

Cannon, C, Nelson, S, Panosian, C, et al, 2001: Soft tissue echinococcosis: A report of two cases and review of literature. Clin. Orthop. Relat. Res. 385:186-91

Casero, R,Cestas, M, Menso, E, 1996: An unusual case of hydatid disease: Localization to the gluteus muscle. Clin. Infect. Dis. 23:395-6.

Chakrabarti, I, Goswami, B, 2012: Primary hydatid cyst of the neck diagnosed by aspiration cytology. Trop. Parasitol. 2, 2:127-8

Chevalier, X, Rhamouni,A, Bretagne, S, et al, 1994:Hydatid cyst of the subcutaneous tissue without other involvement: MR imaging features. AJR, 163:645-6

Daali, M, Hassida, R, 2000: Muscle hydatidosis: 15 cases. Prsse Med. 29, 21:1166-9

Delis, S, Bakoyiannis,A, Exintabelones, T, et al, 2007: Rare localization of the hydatid cyst: Experience from a single center. J. Gastrointest. Surg. 11:195-8

Dirican,A, Unal, B, Kayaalp, C, Kirim- lioglu, V, 2008: Subcutaneous hydatid cysts occurring 
in the palm and thigh: Two case reports. J. Med. Case Rep. 2:273-7

Dudkiewicz, I, Salai, M, Apter, S, 1999: Hydatid cyst presenting as a soft tissue mass in a child. Arch. Orthop. Trauma Surg. 19, 7/8:474-5

Duncan G, Tooke S. 1990: Echinococcus infection of the biceps brachii: A case report. Clin.Orthop.Relat. Res. 261:247-50

Drimousis, P, Stamou, K, Koutras, A, et al, 2006: Unusual site of recurrent muscloskeletalhydatid cyst: Case report and brief review of literature. Wld. Gastroenterol. 12: 5577-8

el-Moussaoui, A, Rabii, R, Rais, H, et al, 1997: Hydatid cyst of the psoas muscle: A propos of a case. Ann. Urol. (Paris), 31, 6/7: 357-60

Eroglu, A, Atabekoglu, S, Kocaoglu, H, 1999: Primary hydatid cyst of the neck. Eur. Arch. Otorhinolaryngol. 254, 4:202-4

Greenberg, S, 2001: Handbook of Neuosurgery. $1^{\text {st }}$ ed. New York, Medical Publisher.

Gupta, V, Tayade, A, Kale, S, 2013: Intramuscular hydatid cyst of adductor magnus: A rare isolated presentation. Nepalese J. Radiol. 3, 1:71-6

Kabiri, el H, Zidane, A, Atoini, F, et al, 2007: Primary hydatid cyst of the posterior mediastinum. Asian Cardiovasc. Ann. 15e: 60-2

Karakas E, Cullu N, Altay N, Ozturk I. 2013: Infected primary hydatid cyst located in sartorius muscle. Indian J. Med. Microbiol. 31, 4:412-4

Katilmis, H, Ozturkcan, S, et al, 2007: Primary hydatid cyst of the neck. Am. J. Ot-olaryngol. Head Neck Med. Surg. 28:205-7

Kazakos, C, Galanis, V, Verettas, D, et al, 2005: Primary hydatid disease in femoral muscles. J. Internat. Med. Res. 33:703-6

Lamine,A, Fikry, T, Zryouil, B, 1993: Primary hydatidosis of the peripheral muscles: 7 cases reports. Acta Orthop. Belg. 59, 2:184-8

Iynen, I, Sogut, O, Gulur, M, et al, 2011: Primary hydatid cyst: an unusual cause of a mass in the supraclavicular region of the neck. J. Clin. Med. Res. 3, 1:52-4

Jarboui S, Hlel, A, Doghfous, A, et al, 2012: Unusual location of primary hydatid cyst: Soft tissue mass in the supraclavicular region of the neck. Case Rep. Med. 2012, ID484638, 4 pp.

Manes, E, Santucci, A, 1990: Echinococcosis: Intramuscular localization. Chir. Organi, Mov. 75, 2:189-96
Marwah, S, Subramanian, P, Marwah, N, et al, 2005: Infected primary intramuscular echinococcosis of the thigh. Indian J. Pediatr. 72:799800

Memis, A, Arkun, R, Bilgen, I, Ustun, E, 1999: Primary soft tissue hydatid disease: Report of two cases with MRI characteristics Eur. Radiol. 9:1101-3

Mseddi, M, Mtaoumi, M, Dahmene, J, et al, 2005: Hydatid cysts in muscles: eleven cases. Rev. Chir. Orthop.Reparatrice Appar. Mot. 91, 3:267-71

Mujtaba, S, Naveen, F, Saroona, H, 2013: Primary hydatid cyst of the neck. J. Coll. Physic. and Surg. Pakistan 23, 11:811-12

Notarnicola,A, Moretti, L, Panella, A, et al, 2009: Case report of a primary multiloculate muscular cystic hydatidosis. Chir.Organi.Mov. 93, 2:79-83

Orhan, Z, Kara, H, Tuzuner, T,et al, 2003: Primary subcutaneous cyst hydatic disease in proximal thigh: an unusual localization: A case report. BMC muscloskeletal Disorders, 4

Ozkoc, G, Akpinar, S, Hersekli, M, et al, 2003: Primary hydatid disease of quadriceps muscle: A rare localization. Arch. Oryhop. Trauma Surg. 123:314-6

Ozturk, S, Devec, M, Yildirim, S, 2001: Hydatid cyst in soft tissue of the face without any primary. Ann. Plast. Surg. 46, 2: 170-3

Palaivelu, C, 2007: Laparoscopic management of hydatid cysts of liver. In: Art of LaParoscopic Surgery. Textbook and Atlas, Jaypee Publishers.

Palmerio, G, Listoto, G, Ranalli, B, et al, 1993: Echinococcal cysts with primary muscle localization: Comments on a clinical case. J. Chir. 14, 2:113-6

Pampori, R, Wani, A, Latoo, M, Hakeem, A, 2003: Hydatid cyst in neck: An unusual presentation. JK-Practitioner 10, 2:130-31

Raza, M, Harris, S, Khan, R, 2003: Hydatid cyst of gall bladder. Indian J. Gastroenterol. 22:67-8

Polat, P, Kantarci, M, Alper, F, et al, 2003: Hydatid disease from head to toe. Radiographics, 23:479-94

Ronki, H, Sotoudeh, H, Sharegh, H, Yazdabadi, A, 2007: A case of primary adductor muscle hydatidosis: "water-lily sign" on magnetic resonance imaging. Iran. J. Radiol. 4, 4:223-6 
Safioleas, M, Stamatakos, M, Zervas, A, Agapitos, E, 2006: Hydatid disease of the seminal vesicle: A rare presentation of hydatid cyst. Int. Urol. Nephrol. 38:287-9

Safioleas M, Nikiteas N, Stamatakos M et al, 2008: Echinococcal cyst of the subcutaneous tissue: A rare case report. Parasitol. Internat. 57:236-8

Sarisoy H, Memisoglu K, Tamer G, Sarlak A, 2008: Primary hydatid disease in adductor muscles. Clin. Invest. Med. 31, 5: E296-9

Satyawati, M, Satheesh, K, Amanjit, B, Mahesh,K, 2013: Primary hydatid cyst presenting as a mass in the subclavicularregioin: case report and literature review. Case Rep. 63, 10:1309-11

Sezer, H, Oztas, M, Ozerhan, I, et al, 2013: Unusual presentation of primary recurrent hydatid cyst. Grand Rounds 13:23-6

Srivastava, P, Gangopadhyay, A, Upadhyaya, V, et al, 2008: An unusual presentation of hydatid cyst in anterior abdominal wall. Kathmandu Univ. Med. J. 6, 4:511-3

Sultana, N, Hashim, T, Jan, S, et al, 2012: Primary cervical hydatid cyst: a rare occurrence. Diagn.Pathol. 7:157-61

Tatari, H, Baron, O, Sanlidag, T, et al, 2001: Primary intramuscular hydatidosis of supraspinatus muscle. Arch. Orthop. Trauma Surg. 121, 1/2: 94-4

Thursky, K, Torresi, J, 2001: Primary muscle hydatidosis of the thigh: Management of a complicated case with combination adjunctive Al- bendazole and Praziquantel chemotherapy. Clin. Infect. Dis. 22:e65-8

Togrul E, Kalaci A, Sarpel Y. et al, 2004: What's your diagnosis? solitaryhydatid cyst of the soleus muscle. Ann. Saudi Med. J. 288:307-9 Turki, I, Turki,A, Khochtali, H,et al,2005: Pterygoidienhydatid cyst. Stomatol. Chir. Maxillofac. 106, 1:27-9

Vicidomini, S, Cancrini, G, Gabrielli, S, et al, 2007: Muscular cystic hydatidosis: Case report. BMC Infect. Dis. 7:23-7

Vietri, F, Illuminati, G, Palumbo, P, Guglielmi, R, 1988: Recurrent primary hydatidosis of Sartorius muscle: Case report. ActaChir. Scand. 154, 9:535-6

Wani, R, Wani I, Malik A et al, 2012: Hydatid disease at unusual sites. IJCRI, 6, 3:1-6

Yilmaz, Y, Ozlugedik, S, Titiz, A, et al, 2007: Hydatid cyst of the neck: a case report. B- ENT 3, 2:83-6

Yorukoglu, Y, Zengin, M, Dolgun, A, et al, 1993: Primary muscular hydatid cyst causing arterial insufficiency: Case report and literature review. Angiol. 44, 5:339-401

Zippi, M, Siliquini, F, Fierro, A, et al, 2007: Diffuse abdominal hydatidosis: Role of magnetic resonance imaging. Clin. Ter. 158, 3:231-3

Zulfikaroglu, B, Koe, M, Ozlap, N, Ozmen,M, 2005: A rare primary location of echinococcal disease: Report of a case. Ups. J. Med. Sci. 110:167-71. 